Check for updates

Cite this: RSC Adv., 2019, 9, 3311

\title{
Preparation, characterization and feasibility analysis of methyl ester of Sesbania seeds oil (MESSO) as alternate liquid dielectrics in distribution transformers
}

\author{
Sujitha Ravulapalli, ${ }^{a}$ Ravindhranath Kunta (D) *a and Mylavarapu Ramamoorty ${ }^{* b}$
}

The methyl ester of Sesbania seed oil (MESSO) was prepared using the transesterification method. The conditions for obtaining the maximum yield of the ester were optimized. The yield was $93.3 \%(\mathrm{v} / \mathrm{v})$ at reaction time of $24 \mathrm{~h}$, catalyst concentration of $4.5 \mathrm{wt} \%$ and methanol to oil volume ratio of $6: 1$. MESSO was characterized by adopting TG-DTA and FT-IR methods. The physical, chemical and electrical properties were measured as per International Standards for assessing its suitability as an insulating liquid in transformers. The kinematic viscosity of the ester is $0.98 \times 10^{-11} \mathrm{~mm}^{2} \mathrm{~S}^{-1}$, which is far less than the viscosity of the raw oil. The low acid/neutralization value $(0.001 \mathrm{mg}$ of $\mathrm{KOH}$ per $\mathrm{g})$ for MESSO offers high oxidation stability. The high flash point $\left(260{ }^{\circ} \mathrm{C}\right)$ and fire point $\left(345^{\circ} \mathrm{C}\right)$ values of MESSO provide operational safety to the transformers when they are filled with the developed insulating fluid. The saturated fatty acid content in MESSO provides a high thermal and oxidation stability for the transformers. The high dielectric constant values for MESSO in comparison to the mineral oil are attributed to the polar groups present in the ester. These results confirm that MESSO can be developed as an alternative to mineral oils for insulation and cooling in transformers. MESSO has merits of low cost, bio-degradability, ecofriendliness and preparation from renewable sources.

Received 9th October 2018 Accepted 7th January 2019 DOI: $10.1039 / \mathrm{c} 8 \mathrm{ra08378a}$ rsc.li/rsc-advances consumption are proportionally depleting. ${ }^{8}$ Hence, exploring the utility of non-edible oils for the specific purpose of insulating the transformers without disturbing the prevailing ecofriendly systems endowed in nature is a progressive aspect of research. The replacement of mineral-based oil with non-edible oils or their derivatives will reduce the production cost and lower the rate of pollution. ${ }^{9}$

This aspect of research is not new. Natural oils such as caster oil, hydrogenated caster oil, cottonseed oil, and coconut oil were used in capacitors before $1990 .^{10}$ A patent for the use of soybean oil with some additives in the capacitor has been issued in $1985 .{ }^{11}$ Since 1990, much interest has been envisaged by researchers in rapeseed oil as transformer oil as it is not an edible oil and available in many countries, and hence needs commercial utility. ${ }^{12}$ Bertrand et al. ${ }^{13}$ probed vegetable oils, namely, castor oil, rapeseed and sunflower oils as substitutes for mineral oils in medium voltage equipment and found that the AC breakdown voltages of these oils was far superior to that of conventional mineral oils. Hosier et al. ${ }^{14}$ studied a wide range of vegetable oils under controlled laboratory aging. The resulting aged oils were characterized by a number of analytical techniques. Kohtoh et al. investigated the effect of aging on the electrical properties of the insulating liquid in field transformers. ${ }^{15}$ Al-Amin et al. probed the use of a silicone-based synthetic ester as an insulating fluid in transformers and
${ }^{a}$ Department of Chemistry, Koneru Lakshmaiah Educational Foundation, Green Fields, Vaddeswaram - 522 502, Guntur District, Andhra Pradesh, India. E-mail: ravindhranath.kunta@gmail.com

${ }^{b}$ Department of Electrical and Electronics Engineering, Koneru Lakshmaiah Educational Foundation, Green Fields, Vaddeswaram - 522 502, Guntur District, Andhra Pradesh, India 
found that this fluid had the capacity to reduce operational risks in transformers. ${ }^{16}$ Thiena et al. investigated palm and coconut oils and found that their breakdown voltages (BDV) were comparable to mineral oil. ${ }^{17}$ Liao et al. showed that though the natural ester, BIOTEMP, had higher acidity and absolute humidity upon aging, its lower relative humidity ratio is beneficial for maintaining the AC breakdown voltage higher than that of mineral oil. ${ }^{18}$ Singha et al. evaluated the comparative characteristics of aging for HONE (high oleic natural ester) and mineral oil (MO) and observed that the dielectric performance of HONE did not alter with aging. ${ }^{19}$ The experimental analyses of Mariprasath et al. on Pongamia pinnata seeds oil revealed that the moisture content reduced considerably during aging and the observed BDV was much higher than that of mineral oil. ${ }^{20}$ $\mathrm{Xu}$ et al. assessed the oxidation stability of vegetable oil, FR3, in terms of OIT (oxidation induction time) at varying temperatures. The experimental results revealed that $130{ }^{\circ} \mathrm{C}$ was the proposed stable operating temperature for oxidation under sealed conditions. ${ }^{21}$ Sitorus et al. assessed the insulation capacity of Jatropha curcas methyl ester oil (JMEO) in comparison with MO by the streamers phenomenon and found that JMEO could be used as a better alternative to MO for high voltage power transformers. ${ }^{22}$ Tokunaga et al. compared the dielectric properties of aged natural esters namely, palm fatty acid ester (PFAE) and FR3 with mineral oil and found that PFAE showed the highest BDV compared with that of the remaining two dielectric fluids. ${ }^{23}$ Villarroel et al. evaluated the moisture diffusion coefficient parameters for two natural esters, namely, BIOTEMP and BIOELECTRA. The results revealed the applicability of moisture dynamics during transformer operation. ${ }^{24}$ The experimental analysis of Mariprasath et al. revealed that the measured physical, chemical and electrical properties of Karanja oil were comparable to those of $\mathrm{MO}^{25}$

The present investigation was aimed to identify a seed that is available widely in India and not used for human or animal consumption (in one form or other) and to investigate the adaptability of the simple esters in the oil extracted from the seeds for transformer insulation. To our knowledge, no successful attempts have been made so far to identify proper seeds available in India whose oils or their derivatives are suitable for use in transformers. We have identified Sesbania seeds (Avisa-in Telugu) for this purpose. In the present investigation, Sesbania seed oil was converted to methyl esters and the obtained methyl ester was characterized for its physical, chemical and electrical properties to determine its suitability as a liquid dielectric in distribution transformers as per the International Standards.

\section{Experimental}

\section{Plant description}

Avisa (in Telugu) or Sesbania grandiflora is commonly called a hummingbird tree. It belongs to the Fabaceae family and grows to a height of $10-15 \mathrm{~m}$ with a trunk diameter of about $30 \mathrm{~cm}$, as shown in Fig. 1(a). It is cultivated for wood and for its seeds, from which oil is obtained. Its origin is India and cosmopolitan in distribution. It flourishes in all climates and

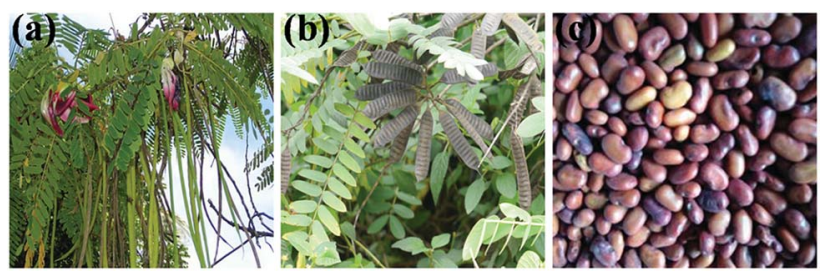

Fig. 1 (a) Sesbania grandiflora plant, (b) Sesbania seed pods and (c) Sesbania seeds.

grows economically in a number of countries around the world, including Sri Lanka, Indonesia, Philippines, and Myanmar. The trees bear pods that are $20-60 \mathrm{~cm}$ long with broad sutures containing 15-50 seeds, as shown in Fig. 1(b). The seeds are dark brown in color and typically about 3 to $4 \mathrm{~mm}$ long, as shown in Fig. 1(c), and contain $30 \%$ to $40 \%$ oil by weight. The potential yield of the seeds is about $500 \mathrm{~kg}$ to $1000 \mathrm{~kg} \mathrm{ha}^{-1}$. The oil is more viscous than other vegetable oils. Therefore, the oil is used in the production of varnishes, printing inks, and paints.

\section{Synthesis of ester}

The seeds were collected, washed with distilled water and air dried. The seeds were then subjected to mechanical crushers to obtain oil. The obtained oil was filtered, refined and used for transesterification.

\section{Purification of oil}

The seed oil was refined by treating the oil with alkali to remove the free fatty acids. This was achieved by adding sodium hydroxide to the oil sample by heating to about $60{ }^{\circ} \mathrm{C}$ for an hour and then centrifuging the sample for a few minutes. Then, the impurities that settled at the bottom were discarded. The purified oil was then subjected to a bleaching process to remove any undesirable coloring materials (other than its natural color) present in the oil. This was done by treating the oil sample with activated carbon derived from the barks of the Ficus racemosa plant for an interval of 30 minutes under agitation. For the preparation of activated carbon, the barks of the Ficus racemosa plant were collected, carbonized at $650{ }^{\circ} \mathrm{C}$ and activated chemically by treatment with $\mathrm{HNO}_{3}$, as described in our previous publication. ${ }^{26}$ The bleached oil was filtered and subjected to a winterization or de-waxing process for removing the frozen saturated fats. For this purpose, the oil was cooled to a freezing temperature $\left(<0{ }^{\circ} \mathrm{C}\right)$ and the fats settled as crystals. These crystals were removed by filtration. The obtained refined, bleached and winterized oil sample was trans-esterified to form esters. The scheme of purification of oil is presented in Fig. 2.

\section{Trans-esterification}

For the transesterification process, a known quantity $(100 \mathrm{~mL})$ of oil sample was mixed with a known quantity $(600 \mathrm{~mL})$ of methanol (in the ratio of $1: 6$ ). ${ }^{27}$ To this blend, $4.5 \mathrm{~mL}$ of conc. $\mathrm{H}_{2} \mathrm{SO}_{4}$ (catalyst) was added. Then, the mixture was refluxed at a temperature of $50{ }^{\circ} \mathrm{C}$ for $24 \mathrm{~h}$. After $24 \mathrm{~h}$ of refluxing, the ester was formed and the mixture was poured into a separating 


\section{$\underline{\text { Purification of Oil }}$}
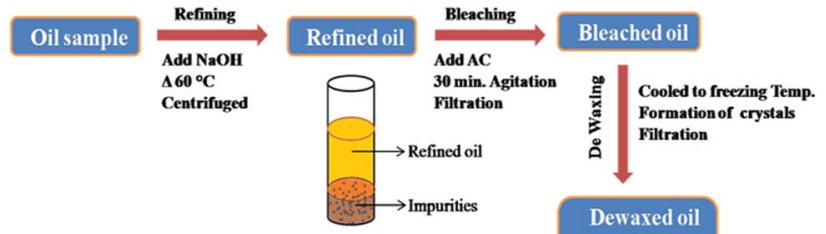

Dewaxed oil

(or)

Purified Oil

Fig. 2 Purification of oil.

funnel. The contents were left overnight for separation. Two layers were formed. The lower layer contained glycerol and the upper layer contained the methyl ester of the Sesbania oil (MESSO). The lower layer was discarded and the upper layer was mixed with hot water to remove the excess catalyst and unreacted methanol. Again two layers were formed; the lower layer was an aqueous layer, which was removed. This washing process was repeated 3 to 4 times until the lower layer was clear. The scheme for the trans-esterification of the oil is presented in Fig. 3. The upper ester layer was centrifuged for a few minutes to remove any water content present in the ester. After centrifugation, the oil layer, if formed, was separated from the aqueous layer. The various parameters affecting the yield were optimized for obtaining a higher\% of the ester. The obtained sample was subjected to characterization.

\section{Characterization}

The fatty acid profile for raw Sesbania oil was determined using the GC-HRMS instrument having an FID detector (Jeol; model ACCuTOF GCV) following the standard procedure as per EN 14103 standard. ${ }^{29}$ The identified fatty acid peaks at various retention times were compared with the retention times of the standards. The measurements were repeated three times and the obtained average values were used for further studies. The

\section{$\underline{\text { Trans-esterification }}$}

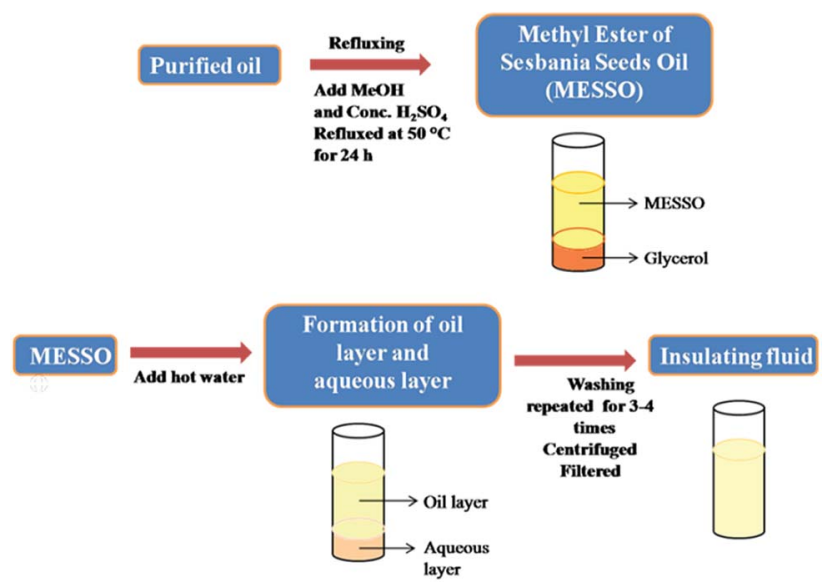

Fig. 3 Transesterification process.
GC-MS spectra of raw Sesbania oil are shown in Fig. 5. Based on the spectra, the $\%$ compositions of different fatty acids were calculated and presented in Tables 2 and 3.

MESSO was characterized using TGD-DGA and FTIR spectroscopy studies. Thermogravimetric analysis was performed using a TGA-DTA Thermal Analyser (Diamond TG-DTA, Perkin Elmer, USA) under air at a temperature range of $50-500{ }^{\circ} \mathrm{C}$ and heating rate of $5{ }^{\circ} \mathrm{C} \mathrm{min}^{-1}$. The obtained data is presented in Fig. 6. The IR spectra were recorded on a BRUKER ALFA FTIR spectrophotometer over the $3600-600 \mathrm{~cm}^{-1}$ range and the spectrum is presented in Fig. 7.

The viscosities of raw oil and MESSO were measured using a rheometer (TA Instrument-Discovery HR1) under air by varying the shear rates. The density of MESSO was measured using a hydrometer. The interfacial tension for MESSO was
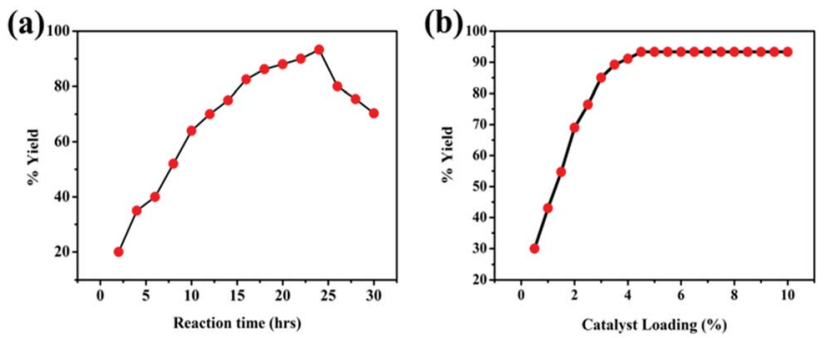

Fig. 4 (a) Effect of reaction time. (b) Effect of catalyst loading on the \% yield of MESSO.

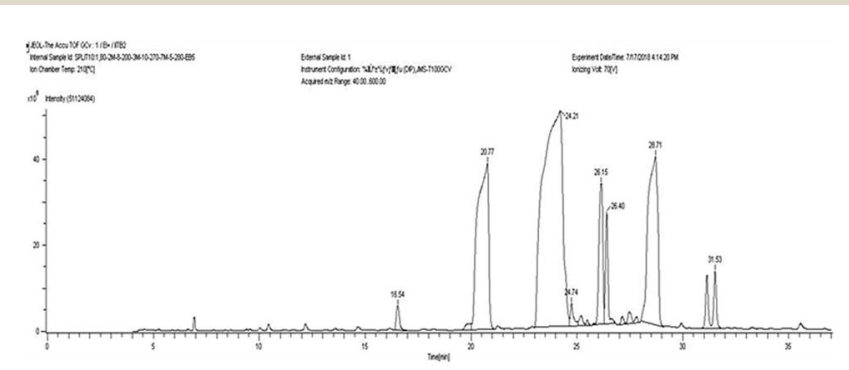

Fig. 5 GC-MS spectra of Sesbania oil.

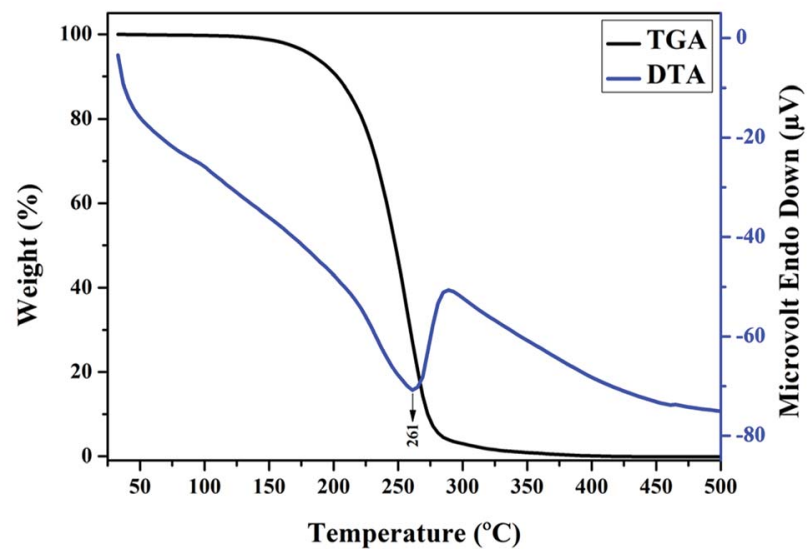

Fig. 6 TGA-DTA analysis of MESSO. 


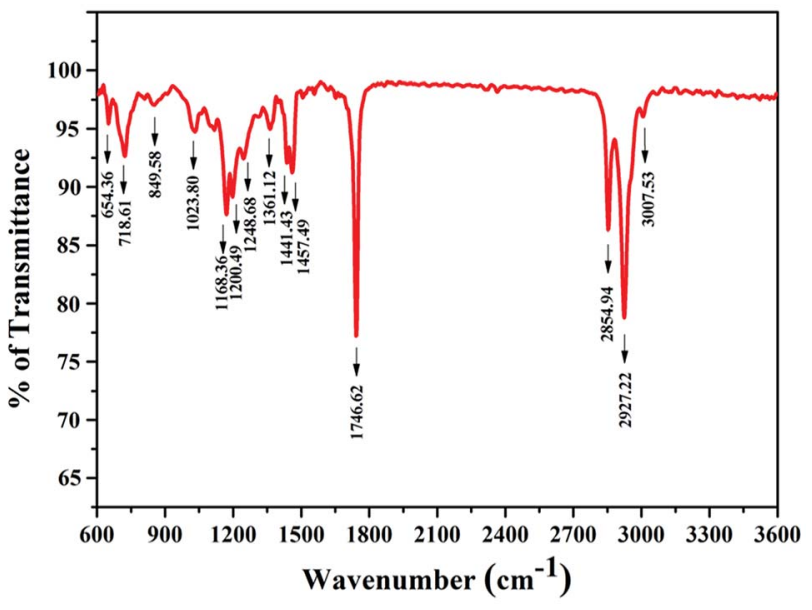

Fig. 7 FTIR spectrum of MESSO.

measured as per IS 6140. The moisture content for MESSO and mineral oil was measured using the Karl Fischer titration method according to IS 13567:1992. The acid or neutralization values for the oil sample and MESSO were measured as a total acid number according to IS 1448 [P:2]:1967.

The dielectric strength of MESSO was measured as per IS 6792:1972. This was determined by using a motorized oil test set (SEV). The flash and fire points for MESSO were measured using a Pensky-Martin closed cup apparatus according to IS 1448(P: 2)-1992. ${ }^{28}$ The $\tan \delta$ values, specific resistance values, dielectric constants and dielectric loss factors of MESSO were measured by performing broadband spectroscopy at the frequency range from $1 \mathrm{~Hz}$ to $\mathrm{MHz}$. All the observed values along with the International Standard limit values are presented in Tables 4 and 5.

\section{Factors affecting the yield of ester, MESSO}

At the end of each run, the volumetric MESSO yield was calculated from the equation

$$
\% \text { Volume yield }=\frac{\text { final volume }}{\text { initial volume }} \times 100
$$

\section{Effect of reaction time}

Contact time is an important factor that affects the rate of the trans-esterification process. The effect of time on transesterification was studied by varying the reaction time from 1 to $30 \mathrm{~h}$ at a constant temperature of $50 \pm 1{ }^{\circ} \mathrm{C}$, stirring speed of $400 \mathrm{rpm}, 4.5 \mathrm{wt} \%$ of catalyst, conc. $\mathrm{H}_{2} \mathrm{SO}_{4}$ loading and $6: 1$ methanol-to-oil ratio. The results are presented in Fig. 4(a). From the Fig. 4(a), it is noted that the rate of trans-esterification is slow at the beginning of the reaction and reached to a maximum yield of $93.3 \%(\mathrm{v} / \mathrm{v})$ at $24 \mathrm{~h}$ of reaction time and then, the yield decreased. The initial slowness of the reaction is attributed to the mixing and dispersion of alcohol into the oil and the slow mass transfer in the reaction mixture. When the time was varied from $15 \mathrm{~h}$ to $24 \mathrm{~h}$, the rate of reaction increased and the yield enhanced from $65.5 \%(\mathrm{v} / \mathrm{v})$ to $93.3 \%(\mathrm{v} / \mathrm{v})$. The fall of yield when the reaction time was more than $24 \mathrm{~h}$ This finding was attributed to the reversed reaction for the transesterification, resulting in more soap generation and the loss of the ester. These observations coincide with well-known chemical principles.

\section{Effect of catalyst loading}

To study the effect of catalyst loading, the amount of catalyst was varied from 0.5 to $10 \mathrm{wt} \%$ with respect to oil weight under the following optimum reaction conditions: methanol-to-oil volume ratio, $6: 1(\mathrm{v} / \mathrm{v})$; temperature, $50 \pm 1{ }^{\circ} \mathrm{C}$; stirring speed, $400 \mathrm{rpm}$; time, $24 \mathrm{~h}$. These observations are presented in Fig. 4(b). It was inferred from Fig. 4(b) that the rate of reaction increased with the increase in the catalyst amount from 0.5 to $5 \mathrm{wt} \%$, and a maximum yield of $93.3 \%(\mathrm{v} / \mathrm{v})$ MESSO was achieved with the catalyst amount of $4.5 \mathrm{wt} \%$, after which it became constant. ${ }^{30}$ This finding was attributed to the increase in the active sites with an increase in the amount of catalyst till steady state was reached. When all the active sites were used up, the rate of reaction became constant. ${ }^{31}$

\section{Effect of the oil to methanol volume ratio}

The effect of the methanol to oil volume ratio was studied by varying the methanol-to-oil volume ratio from $1: 1$ to $12: 1$, keeping the other operating conditions at optimum levels. The findings are noted in Table 1. It is inferred from the table that as the content of methanol increases, the \% yield of MESSO increases up to the volume ratio of $6: 1$, and any further increase in methanol volume adversely affects the yield. To increase the dissolution of oil in methanol, a higher amount of methanol is required. ${ }^{32}$ The conversion of triglycerides from fatty acids to glycerol and methyl esters required three steps: conversion of triglycerides to di-glycerides, di-glycerides to mono-glycerides and finally mono-glycerides to free glycerol and methyl esters. ${ }^{33}$ All these steps are reversible reactions and to achieve higher yields, higher content of methanol is needed to shift the reaction for more formation of esters. ${ }^{34}$ However, when the content of methanol is very high, trans-esterification is adversely affected. This is attributed to the fact that as the content of methanol increases, the polarity of the reaction mixture increases and this results in an increase in the solubility of glycerol in the ester layer. Moreover, the higher percentage of methanol dilutes the activity of the catalyst by

Table 1 Effect of methanol to oil volume ratio on the \% yield

\begin{tabular}{lll}
\hline S. no. & $\begin{array}{l}\text { Methanol to oil } \\
\text { volume ratio }\end{array}$ & $\begin{array}{l}\text { \% Yield } \\
\text { of the ester }\end{array}$ \\
\hline 1 & $1: 1$ & 15.5 \\
2 & $2: 1$ & 28.9 \\
3 & $4: 1$ & 62.5 \\
4 & $6: 1$ & 93.3 \\
5 & $8: 1$ & 59.0 \\
6 & $10: 1$ & 38.7 \\
7 & $12: 1$ & 22.4
\end{tabular}


blocking $\mathrm{H}^{+}$or functional groups of the triglycerides. ${ }^{35}$ In the present trans-esterification, the optimum methanol to oil ratio was found to be $6: 1$.

\section{Results and discussions}

\section{Fatty acids composition of Sesbania oil}

The GC-MS spectrum of raw Sesbania oil is shown in Fig. 5. Based on this spectrum, the \% compositions of the different fatty acids were calculated and presented in Table 2 . The degree of unsaturation (DU) for the raw Sesbania oil and MESSO was calculated using the following equation: Degree of unsaturation $(\mathrm{DU})=\left(\right.$ monounsaturated $\left.\mathrm{C}_{n}: 1, \mathrm{wt} \%\right)+2$ (polyunsaturated $\mathrm{C}_{n}$ : 2 , wt $\%)+5$ (polyunsaturated $\mathrm{C}_{n}: 5$, wt $\left.\%\right) .{ }^{39}$ The results are presented in Table 3.

From the tables, it is seen that the saturated fatty acid content in Sesbania oil was $26.99 \mathrm{wt} \%$, which imparted higher oxidative and thermal stabilities, leading to a slower deterioration rate for the lipid characteristics. ${ }^{40,41}$ This tendency makes MESSO a good insulating fluid in transformers to withstand high-temperature environments or long-term storage conditions.

\section{TG-DTA}

TG-DTA analysis was used to estimate the nature and number of constituents present in the ester sample. The TGA data depicted in Fig. 6 shows that thermal decomposition occurred in a single stage. This indicates that MESSO was thermally stable. As the temperature increased from 50 to $100{ }^{\circ} \mathrm{C}$, no significant loss in the $\mathrm{wt} \%$ of the sample was observed, which confirmed the that less moisture content was present in the sample and $97 \mathrm{wt} \%$ of the sample was retained until $200{ }^{\circ} \mathrm{C}$. After $200{ }^{\circ} \mathrm{C}$, thermal decomposition slowly initiated and became significant after

Table 2 Fatty acid profile of Sesbania oil

\begin{tabular}{lc}
\hline Fatty acid & $\begin{array}{l}\text { Sesbania oil } \\
\text { (wt\% composition) }\end{array}$ \\
\hline Myristic acid C14:0 & 0.85 \\
Palmitic acid C16:0 & 19.96 \\
Oleic acid C18:1 & 46.64 \\
Linoleic acid C18:2 & 0.79 \\
Eicosapentaenoic acid C20:5 & 7.47 \\
Arachidic acid C20:0 & 3.09 \\
Erucic acid C22:1 & 17.71 \\
Palmitoleic acid C16:1 & 0.40 \\
Lignoceric acid C24:0 & 3.09
\end{tabular}

Table 3 Type of fatty acids in Sesbania oil

\begin{tabular}{ll}
\hline Type of fatty acid & $\begin{array}{l}\text { Sesbania oil } \\
\text { (wt\% composition) }\end{array}$ \\
\hline Saturated & 26.99 \\
Monounsaturated & 65.93 \\
Polyunsaturated & 7.08 \\
The degree of unsaturation (DU) & 99.23
\end{tabular}

$250{ }^{\circ} \mathrm{C}$. At $261{ }^{\circ} \mathrm{C}$, the wt $\%$ loss was about $73 \%$. This result was attributed to the flash point of MESSO, which was always less than the final decomposition temperature. A substantial mass loss from $73 \%$ to $100 \%$ in the temperature range from $261{ }^{\circ} \mathrm{C}$ to $345{ }^{\circ} \mathrm{C}$ is observed. Complete decomposition of the sample was noted at $345{ }^{\circ} \mathrm{C}$, indicating the fire point of MESSO. These results confirmed the purity of the sample and its thermal stability. The corresponding DTA results are also shown in Fig. 6. These results confirm the endothermic nature of the sample and infer that MESSO can be used as the insulating fluid in transformers.

\section{FTIR}

The IR spectrum of MESSO (Fig. 7) shows various peaks pertaining to an ester, confirming the formation of an ester. The absorption peak at $3007 \mathrm{~cm}^{-1}$ is attributed to $-\mathrm{OH}$ groups. ${ }^{36}$ The absorption peaks at 2927 and $1436 \mathrm{~cm}^{-1}$ are attributed to the symmetric and anti-symmetric vibrations of $-\mathrm{CH}_{2}$ groups. The stretching peaks at $1746 \mathrm{~cm}^{-1}(\mathrm{C}=\mathrm{O}), 1023 \mathrm{~cm}^{-1}$ and $1200 \mathrm{~cm}^{-1}(-\mathrm{C}-\mathrm{O}-)$ confirm the presence of the ester.

\section{Physical parameters}

Kinematic viscosity. The dynamic viscosities of raw Sesbania oil and MESSO were noted at varying shear rates. The results obtained are plotted as the shear rate $v s$. viscosity in Fig. 8. It is observed that the dynamic viscosity of $\operatorname{MESSO}\left(0.82 \times 10^{-2} \mathrm{~Pa} \mathrm{~s}\right)$ is less than that of the pure oil $\left(7.4 \times 10^{-2} \mathrm{~Pa} \mathrm{~s}\right)$ at a shear rate of $110 \mathrm{~S}^{-1}$.

From the values of dynamic viscosity, kinematic viscosities of the oil and MESSO were calculated based on the formula:

$$
\text { Kinematic viscocity }=\frac{\text { dynamic viscocity }}{\operatorname{density}(\rho)}
$$

The kinematic viscosity for MESSO was $0.98 \times 10^{-11} \mathrm{~mm}^{2}$ $\mathrm{S}^{-1}$, which was far less than that of Sesbania oil $\left(9.48 \times 10^{-11}\right.$ $\left.\mathrm{mm}^{2} \mathrm{~S}^{-1}\right)$. The major reason for the viscosity reduction was the transformation of triglycerides to methyl esters. MESSO was induced to flow easily at a low viscosity. ${ }^{37}$ This finding fulfills one of the important conditions for MESSO for its suitability as an insulating fluid in transformers.

Density. The density of MESSO was found to be $0.84 \mathrm{~g} \mathrm{~cm}^{-3}$, which was within the permitted International Standard value of $0.89 \mathrm{~g} \mathrm{~cm}^{-3}$.

Interfacial tension. The interfacial tension between the interface of water and oil is a way to measure the molecular attractive forces between water and oil. It is measured in newton per meter or dyne percm. This value is useful for determining the presence of polar contaminants and oil decay products. Fresh oil generally exhibits high interfacial tension. The present MESSO has interfacial tension of $0.038 \mathrm{~N} \mathrm{~m}^{-1}$, which was comparable to the International Standard value of $0.04 \mathrm{~N} \mathrm{~m}^{-1}$ (Table 4).

Flash and fire points. Flashpoint is one of the most important variables used to characterize the fire and explosion hazards of liquids. The flash and fire points for MESSO were 
(a)

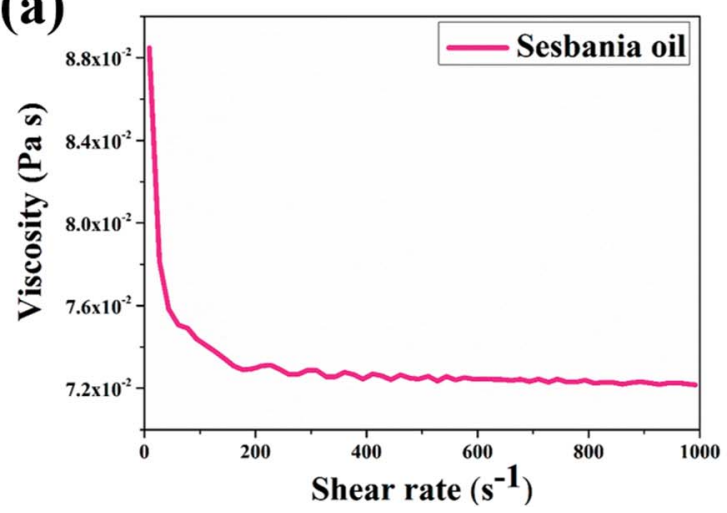

(b)

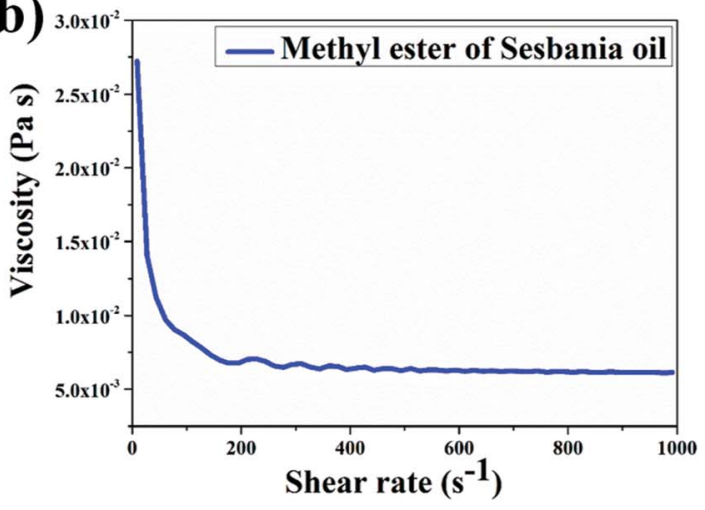

Fig. 8 Shear rate vs. viscosity.

Table 4 Measured physical properties for the ester (MESSO)

\begin{tabular}{|c|c|c|c|c|c|}
\hline & Kinematic viscosity @ $40^{\circ} \mathrm{C}, \mathrm{mm}^{2} \mathrm{~S}^{-1}$ & Density $\mathrm{g} \mathrm{cm}^{-3}$ & $\begin{array}{l}\text { Interfacial tension } \\
\text { (IFT) } \mathrm{N} \mathrm{m}^{-1}\end{array}$ & Flashpoint $\left({ }^{\circ} \mathrm{C}\right)$ & $\begin{array}{l}\text { Fire point } \\
\left({ }^{\circ} \mathrm{C}\right)\end{array}$ \\
\hline IS limit \& value & - & IS 1448 [P:16], <0.89 & IS $6104,0.04$ & IS 1448 [P:21], >140 & $>180$ \\
\hline
\end{tabular}

measured and presented in Table 4 . It is noted from the table that the flash point of $260^{\circ} \mathrm{C}$ and fire point of $345^{\circ} \mathrm{C}$ for MESSO are within the International Standards for transformer oils.

\section{Chemical parameters}

Moisture content. The moisture content present in MESSO and conventional mineral oil was measured at various temperatures ranging from $40-120{ }^{\circ} \mathrm{C}$ using the Karl Fischer titration method. The observations are presented in Fig. 9 as 'Temperature vs. moisture content'. It is observed from the figure that the moisture content decreases with the increase in the temperature for both MESSO and mineral oil (MO).

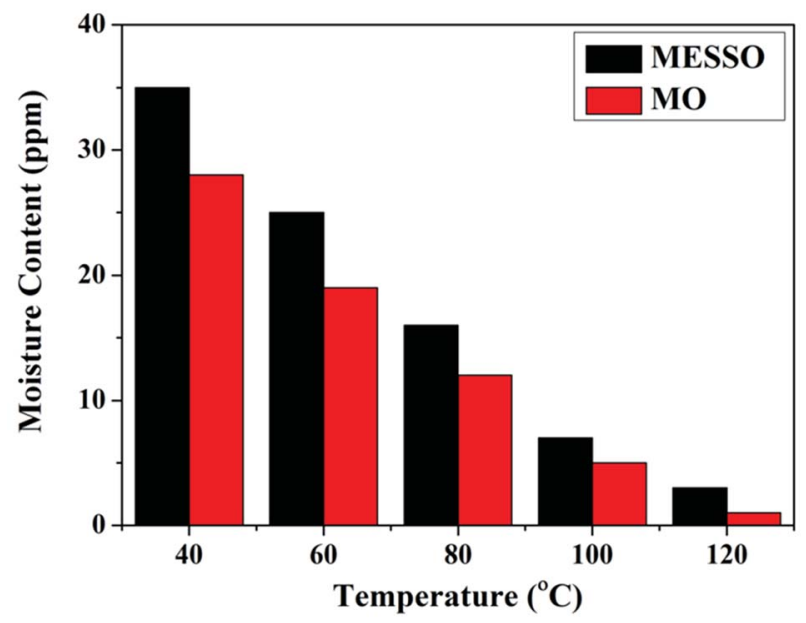

Fig. 9 Temperature vs. moisture content.
Kraft paper and pressboard were used for solid insulation in the transformers. These comprised D-glucose monomers, which were polymerized to form cellulose. If the \% of moisture content is more in the transformer oil, the degradation of the cellulose polymer and the reduction of the dielectric strength occurs. The moisture content of MESSO was found to be $35 \mathrm{ppm}$ at $40{ }^{\circ} \mathrm{C}$, which was within the permitted International Standard limit of $<50 \mathrm{ppm}$. Therefore, MESSO satisfied another important condition for transformer oils.

Acid/neutralization value. The degree of purity, aging and quality for the oil upon storage were indicated by the acid/ neutralization value. ${ }^{38}$ The acid/neutralization value for the oil and MESSO was measured as per the International Standards. The values are presented in Table 5 . It is noted from the table that the acid value for MESSO $\left(0.001 \mathrm{mg}\right.$ of $\left.\mathrm{KOH} \mathrm{g}^{-1}\right)$ was far less than that of mineral oil.

\section{Electrical parameters}

Dielectric strength or AC break down voltage. The breakdown voltage for MESSO was found to be $24 \mathrm{kV}$, which was comparable to the dielectric strength of mineral oil $(30 \mathrm{kV})$.

Dielectric constant $\left(\varepsilon^{\prime}\right)$ and dielectric loss factor $\left(\varepsilon^{\prime \prime}\right)$. The dielectric constant $\left(\varepsilon^{\prime}\right)$ and dielectric loss factors $\left(\varepsilon^{\prime \prime}\right)$ for MESSO were calculated by varying the frequencies from $10 \mathrm{~Hz}$ to $1 \mathrm{MHz}$. Fig. 10 shows the effect of frequency on the dielectric constant $\varepsilon^{\prime}$ for MESSO at a temperature of $30{ }^{\circ} \mathrm{C}$.

MESSO had higher dielectric constant values than the conventional mineral oil (MO). This could be attributed to the fact that MESSO is an ester that possesses many polar groups such as $\mathrm{C}=\mathrm{O}$ and $\mathrm{C}-\mathrm{O}$ - that cause orientation polarization in addition to atomic and electronic polarizations. In the case of 
Table 5 Measured chemical and electrical properties of the ester (MESSO)

\begin{tabular}{|c|c|c|c|c|c|}
\hline & $\begin{array}{l}\text { Moisture content } \\
\text { at } 40{ }^{\circ} \mathrm{C}(\mathrm{ppm})\end{array}$ & Acid value & $\begin{array}{l}\text { AC breakdown voltage } \\
(\mathrm{kV})\end{array}$ & Tan delta & $\begin{array}{l}\text { Specific resistance } \\
(\mathrm{M} \Omega)\end{array}$ \\
\hline IS limit \& value & IS13567, <50 & IS 1448 [P:2], $0.03 \mathrm{mg}$ of $\mathrm{KOH}$ per $\mathrm{g}$ & IS $6792,>30$ & IS $6262,>1.58^{\circ}$ & - \\
\hline Ester (MESSO) & 35 & $0.001 \mathrm{mg}$ of $\mathrm{KOH}$ per $\mathrm{g}$ & 24 & $1.83^{\circ}$ & 514 \\
\hline
\end{tabular}

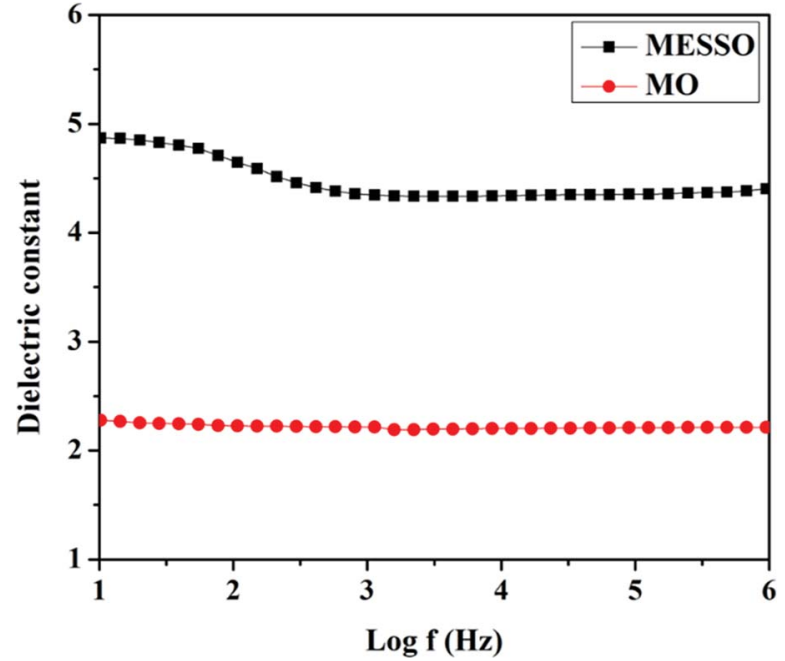

Fig. $10 \log f v s$. dielectric constant.

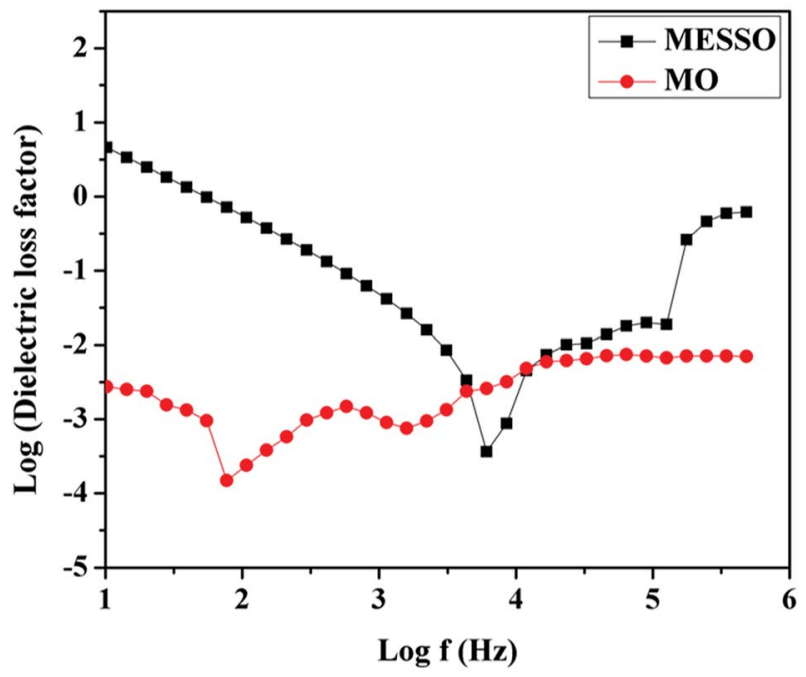

Fig. $11 \log f$ vs. $\log$ (dielectric loss factor).

mineral oil, only non-polar alkane groups were present, resulting in only atomic and electronic polarizations and not oriental polarization, thus resulting in low values. ${ }^{42}$ The high dielectric constant value for MESSO indicated that the ester has more merits than mineral (petroleum) oils in terms of the characterization of the transformer oils because the higher dielectric values of impart more cooling and safety to the transformers.

The dielectric loss factor $\left(\varepsilon^{\prime \prime}\right)$ for MESSO and mineral oil were measured over the frequency range from $10 \mathrm{~Hz}$ to $1 \mathrm{MHz}$ at a fixed temperature of $30{ }^{\circ} \mathrm{C}$. The results are presented in Fig. 11. The $\varepsilon^{\prime \prime}$ for the insulating materials was ascribed to factors pertaining to the conduction process and polarization phenomena. As the esters are endowed with polar groups, it is expected that the conductance increases with the increase in frequency. Polarization phenomenon also causes an increase in $\varepsilon^{\prime \prime}$ values with the rise in frequency. From the plot of $\varepsilon^{\prime \prime} v s . \log f$ taken at $30{ }^{\circ} \mathrm{C}$ (Fig. 11), it is seen that $\varepsilon^{\prime \prime}$ for MESSO as well as MO exhibited frequency dependence. ${ }^{43}$

In the case of MESSO, the $\varepsilon^{\prime \prime}$ value is decreased from $10 \mathrm{~Hz}$ to $6000 \mathrm{~Hz}$ and it may be mainly due to the increase in polarization effect that results in the increase in dielectric constant. After this $\varepsilon^{\prime \prime}$ value, there is an increase up to $17212 \mathrm{~Hz}$ and then, it almost remains constant up to $133045 \mathrm{~Hz}$ and finally the value increase with the rise in frequency. In the case of mineral oil, the $\varepsilon^{\prime \prime}$ values decrease with an increase in the frequency from $10 \mathrm{~Hz}$ to $77.62 \mathrm{~Hz}$ and then increase up to $575 \mathrm{~Hz}$. The values fall, rise and become constant in the frequency range from $12022 \mathrm{~Hz}$ to $488652 \mathrm{~Hz}$. At higher frequencies, the conductivity of MESSO increases due to the presence of polar groups, resulting in an increase in the dielectric loss factor.

Tan delta/dielectric dissipation factor. Dissipation factor $=$ $\tan \delta=\varepsilon^{\prime \prime} / \varepsilon^{\prime}$. This is the index term for assessing the quality of the oil. The dielectric dissipation factor for MESSO is much higher than that of mineral oil, as given in Table 5. The observed value was 1.830 , which was more than the International Standard permitted value of $>1.580$. The stability of the methyl ester, MESSO compared to its raw oil may be ascribed to its chemical composition and inter/intramolecular interactions. The parent oil being a glycerol ester has more polar groups, while MESSO being a methyl ester has relatively fewer polar groups. This enabled the latter to be less reactive and more stable than the raw oil.

Specific resistivity. The specific resistivity for MESSO was 514 $\mathrm{M} \Omega$, which was much higher than that of the conventional mineral oil ( $>50 \mathrm{M} \Omega$, Table 5). This confirms one of the important features of transformer oils. The higher specific resistivity for MESSO reflects the high breakdown strength and low dielectric losses.

\section{Conclusions}

In the present investigation, methyl ester was synthesized from the oil of Sesbania grandiflora (AVISA in Telugu) seeds by the trans-esterification method and the conditions were optimized for obtaining maximum \% yield. It is found that with an optimum reaction time of $24 \mathrm{~h}$, a catalyst concentration of $4.5 \mathrm{wt} \%$ and a methanol to oil volume ratio of $6: 1$, the yield was 
93.3\% (v/v). The methyl ester of the Sesbania seeds oil (MESSO) was characterized via TG-DTA and FTIR spectroscopy.

The physical, chemical and electrical properties were measured as per International Standards for assessing its suitability as an insulating liquid in transformers. The physical/ chemical properties such as viscosity, density, interfacial tension, moisture content, and the acid/neutralization value were within the International Standard permissible limit of insulating oils. The saturated fatty acid content in MESSO retarded the deterioration of the insulating fluid in hightemperature environments or long-term storage conditions. Electrical parameters such as tan delta and specific resistivity were much higher than those of the mineral oil. The dielectric constant and dielectric loss were found to vary with frequencies both for MESSO and MO. The dielectric constant values were higher for MESSO than MO, which was attributed to the polar groups present in the ester. The higher values imparted more cooling ability and high insulation capacity for the ester compared to MO. These results show the suitability of MESSO as a liquid dielectric. MESSO derived from natural plants offers an interesting alternative to mineral oils for insulation and cooling in a transformer due to its bio-degradability, ecofriendly nature, extraction from renewable sources and lowcost.

\section{Conflicts of interest}

There are no conflicts to declare.

\section{References}

1 L. F. Chuah, A. R. Abd Aziz, S. Yusup, A. Bokhari, J. J. Klemes and M. Z. Abdullah, Performance and emission of a diesel engine fuelled by waste cooking oil methyl ester derived from palm olein using hydrodynamic cavitation, Clean Technol. Environ. Policy, 2015, 17, 2229.

2 I. Fernandez, A. Ortiz, F. Delgado, C. Renedo and S. Perez, Comparative evaluation of alternative fluids for power transformers, Electr. Power Syst. Res., 2013, 98, 58-69.

3 M. Brondani, R. Hoffmann, F. D. Mayer and J. S. Kleinert, Environment and energy analysis of biodiesel production in Rio Grande do Sul, Brazil, Clean Technol. Environ. Policy, 2015, 17(1), 129-143.

4 D. Singh, A. Ganesh and S. Mahajani, Heterogeneous catalysis for biodiesel synthesis and valorization of glycerol, Clean Technol. Environ. Policy, 2015, 17(4), 11031110.

5 R. G. Pereira, O. E. P. Tulcan, C. E. Fellows, V. D. J. Lameira, O. L. G. Quelhas, M. E. D. Aguiar and D. M. D. E. S. Filho, Sustainability and mitigation of greenhouse gases using ethyl beef tallow biodiesel in energy generation, J. Cleaner Prod., 2012, 29-30, 269-276.

6 D. O'Connell, M. Savelski and C. Stewart Slater, Life cycle assessment of dewatering routes for algae-derived biodiesel processes, Clean Technol. Environ. Policy, 2013, 15, 567-577.

7 L. F. Chuah, A. Bokhari, S. Yusup, J. J. Klemes, M. M. Akbar and S. Saminathan, Optimization on pretreatment of kapok seed (Ceiba pentandra) oil via esterification reaction in an ultrasonic cavitation reactor, Biomass Convers. Biorefin., 2017, 7, 91.

8 K. Tan, K. Lee and A. Mohamed, Potential of waste palm cooking oil for catalyst-free biodiesel production, Energy, 2011, 36, 2085-2088.

9 M. Rafiqa, Y. Z. Lva and Y. Zhoua, Use of vegetable oils as transformer oils-a review, Renewable Sustainable Energy Rev., 2015, 52, 308-324.

10 K. M. Kamath and C. S. Lakshmin, Variation of dielectric properties of some vegetable oils in the liquid-solid transition phase, Indian J. Technol., 1971, 312-313.

11 V. Shedigian, Non-toxic impregnate for electrical capacitors, US Pat., 4536331, Emhart Industries, Inc., Indianapolis, IN, 1985.

12 I. Moumine, B. Gosse, J. P. Gosse, R. Clavreul and C. Hantouche, Vegetable oil as an impregnate in HV AC capacitors, Proceedings of 1995 IEEE 5th International Conference on Conduction and Breakdown in Solid Dielectrics, 1995, pp. 611-615.

13 Y. Bertrand and L. C. Hoang, Vegetable oils as a substitute for mineral oils in medium voltage equipment, CIGRÉ, 2004, D1202.

14 I. L. Hosier, A. Guushaa, A. S. Vaughan and S. G. Swingler, Selection of a suitable vegetable oil for high voltage insulation applications, J. Phys.: Conf. Ser., 2009, 183, 012014.

15 M. Kohtoh, S. Kaneko, S. Okabe, T. K. Egasaki-Cho and K. Yokoham, Aging effect on electrical characteristics of insulating oil in field transformer, IEEE Trans. Dielectr. Electr. Insul., 2009, 6, 1198-1706.

16 H. Al-Amin, J. OBrien and M. Lashbrook, Synthetic ester transformer fluid: a total solution to wind park transformer technology, Renewable Energy, 2013, 49, 33-38.

17 Y. V. Thiena, N. Azisa and J. Jasnia, The effect of polarity on the lightning breakdown voltages of palm oil and coconut oil under a non-uniform field for transformers application, Ind. Crops Prod., 2016, 89, 250-256.

18 R. Liao, J. Hao, G. Chen, Z. Ma and L. Yang, A comparative study of physico chemical, dielectric and thermal properties of pressboard insulation impregnated with natural ester and mineral oil, IEEE Trans. Dielectr. Electr. Insul., 2011, 18(5), 1626-1637.

19 S. Singha, F. George, C. Clair Claiborne and D. Cherry, Comparative aging characteristics between a high oleic natural ester dielectric liquid and mineral oil, IEEE Trans. Dielectr. Electr. Insul., 2014, 21(1), 149-158.

20 T. Mariprasath and V. Kirubakaran, Pongamia pinnata as alternate liquid dielectrics in distribution transformer: a critical study on the property of viscosity, Advances in Energy and Power, 2015, 3(1), 1-7.

21 Y. Xu, Q. Sen, Q. Liu and Z. D. Wang, Oxidation stability assessment of vegetable transformer oil under thermal aging, IEEE Trans. Dielectr. Electr. Insul., 2014, 21(2), 683692.

22 H. B. H. Sitorus, A. Beroual, R. Setiabudy and S. Bismo, Prebreakdown phenomena in new vegetable oil-based Jatropha 
curcas seeds as a substitute of mineral oil in high voltage equipment, IEEE Trans. Dielectr. Electr. Insul., 2015, 22(5), 2442-2448.

23 J. Tokunaga, H. Koide, K. Mogami and T. Hikosaka, Comparative studies on the aging of thermally upgraded paper insulation in palm fatty acid ester, mineral oil, and natural ester, IEEE Trans. Dielectr. Electr. Insul., 2016, 23(1), 258-265.

24 R. Villarroel, D. F. Garcya, B. Garcya and J. C. Burgos, Moisture diffusion coefficients of transformer press board insulation impregnated with natural esters, IEEE Trans. Dielectr. Electr. Insul., 2015, 22(1), 581-589.

25 T. Mariprasath, V. Kirubakaran and D. Kalyana Kumar, Feasibility analysis of Karanja oil as alternate liquid dielectrics for distribution transformers, International Transactions on Electrical Energy Systems, 2017, 27, e2345.

26 R. Sujitha and K. Ravindhranath, Defluoridation studies using active carbon derived from the barks of Ficus racemosa plant, J. Fluorine Chem., 2017, 193, 58-66.

27 L. F. Chuah, S. Yusup, A. R. Abd Aziz, A. Bokhari and M. Z. Abdullah, Cleaner Production of Methyl Ester using Waste Cooking Oil Derived from Palm Olein using a Hydrodynamic Cavitation Reactor, J. Cleaner Prod., 2016, 112(5), 4505-4514.

28 IS 1448-21, Petroleum and its products-methods of the test, part 21: flash point (closed) by Pensky Martens apparatus, 1992.

29 D. Ghayal, A. B. Pandit and V. K. Rathod, Optimization of biodiesel production in a hydrodynamic cavitation reactor using used frying oil, Ultrason. Sonochem., 2013, 20, 322-328.

30 L. F. Chuaha, J. J. Klemesc, S. Yusupa, A. Bokharia and M. M. Akbar, A review of cleaner intensification technologies in biodiesel production, J. Cleaner Prod., 2017, 146(10), 181-193.

31 A. A. Al-Saadi, T. A. Saleh and V. K. Gupta, Spectroscopic and computational evaluation of cadmium adsorption using activated carbon produced from rubber tires, J. Mol. Liq., 2013, 188, 136-142.

32 L. F. Chuah, J. J. Klemes, S. Yusup, A. Bokharia, M. M. Akbar and Z. Kai Chong, Kinetic studies on waste cooking oil into biodiesel via hydrodynamic cavitation, J. Cleaner Prod., 2017, 146, 47-56.

33 A. N. Phan and T. M. Phan, Biodiesel production from waste cooking oils, Fuel, 2008, 87, 3490-3496.

34 Q. Shu, J. Gao, Z. Nawaz, Y. Liao, D. Wang and J. Wang, Synthesis of biodiesel from waste vegetable oil with large amounts of free fatty acids using a carbon-based solid acid catalyst, Appl. Energy, 2010, 87, 2589-2596.

35 J. Qian, H. Shi and Z. Yun, Preparation of biodiesel from Jatropha curcas L. oil produced by two-phase solvent extraction, Bioresour. Technol., 2010, 101, 7025-7031.

36 L. F. Chuah, M. M. Amin, S. Yusup, N. A. Raman, A. Bokhari, J. J. Klemešc and M. Sahban Alnarabiji, Influence of green catalyst on transesterification process using ultrasonicassisted, J. Cleaner Prod., 2016, 136(B), 14-22.

37 L. F. Chuah, A. Bokhari, S. Yusup, J. J. Klemeš, B. Abdullah and M. M. Akbar, Optimisation and Kinetic Studies of Acid Esterification of High Free Fatty Acid Rubber Seed Oil, Arabian J. Sci. Eng., 2016, 41, 2515.

38 L. F. Chuah, S. Yusup, A. R. Abd Aziz, J. J. Klemes, A. Bokhari and M. Z. Abdullah, Influence of fatty acids content in nonedible oil for biodiesel properties, Clean Technol. Environ. Policy, 2016, 18, 473.

39 L. F. Chuah, J. J. Klemes, S. Yusup, A. Bokhari and M. M. Akbar, Influence of fatty acids in waste cooking oil for cleaner biodiesel, Clean Technol. Environ. Policy, 2017, 19, 859.

40 C.-Y. Lin. and Yi-W. Lin, Fuel Characteristics of Biodiesel Produced from a High-Acid Oil from Soybean Soapstock by Supercritical-Methanol Transesterification, Energies, 2012, 5, 2370-2380.

41 C. Y. Lin and C. C. Chiu, Characteristics of palm-oil biodiesel under long-term storage conditions, Energy Convers. Manage., 2010, 51, 1464-1467.

42 Z. H. Shah and Q. A. Tahir, Dielectric Properties of Vegetable Oils, Journal of Scientific Research, 2011, 3(3), 481-492.

$43 \mathrm{~L}$. Hu, K. Toyoda and I. Ihara, Dielectric properties of edible oils and fatty acids as a function of frequency, temperature, moisture, and composition, J. Food Eng., 2008, 88, 151. 